\title{
Dramatic decline in orang-utan numbers in the Leuser Ecosystem, Northern Sumatra
}

\author{
Carel P. van Schaik, Kathryn A. Monk and J. M. Yarrow Robertson
}

\begin{abstract}
The Leuser Ecosystem, northern Sumatra, Indonesia, contains the world's largest orang-utan Pongo pygmaeus population. We examine the consequences of the recent wave of forest conversion, and legal and illegal logging, on orang-utan numbers in the Leuser Ecosystem. We review density variation inside the Leuser Ecosystem and its causes, and the consequences of selective logging, exhaustive logging and clear-felling for habitat conversion on orang-utan densities. The analysis of the orang-utan's decline is based on information on forest loss, logging intensity, and the delin-
\end{abstract}

eation of logging concessions and legal changes in land use status. The results indicate a very rapid decline, by c. 45 per cent, from c. 12,000 in early 1993 , over a 6 - to 7-year period. During 1998 and 1999, losses occurred at a rate of about 1000 orang-utans per year. At this rate, further losses in the near future are expected to put the survival of Leuser's orang-utans in serious doubt.

Keywords Conversion, fragmentation, illegal logging, orang-utan, plantations, selective logging, Sumatra.

\section{Introduction}

During the Pleistocene, orang-utans Pongo pygmaeus occurred throughout South-east Asia: all the way from Java to the Tropic of Cancer in Southern China (von Koenigswald, 1982). Since then, their distribution has shown a dramatic decline. Currently, they are only found in a tiny fragment of the former range: parts of the islands of Borneo and Sumatra, each of which has a distinct subspecies.

This dramatic decline can realistically be ascribed to two causes only: climate change and hunting by humans. Climate change may have played a role, but, even if during glacial maxima lowland rain forests were much more limited than today, there should have been enough time to recolonize coastal Indo-China and the Malay Peninsula, where orang-utans are now absent. It is more likely, therefore, that orang-utans have narrowly escaped becoming a victim of the great overkill, the extermination of many large vertebrates following the colonization of a region by humans (Brown \& Lomolino, 1998). The caves in the Padang highlands in West Sumatra and in Niah in Sarawak, inhabited by the early human colonists who started to invade the region about

Carel P. van Schaik (corresponding author) Department of Biological Anthropology and Anatomy, Duke University, Box 90383, Durham, NC 27708-0383, USA. E-mail: carel.vanschaik@duke.edu

Kathryn A. Monk Research, Monitoring, and Information Division, Leuser Management Unit, Jl. Dr Mansyur 68, Medan 20154, Indonesia

J. M. Yarrow Robertson Conservation Management Division, Leuser Management Unit, Jl. Dr Mansyur 68, Medan 20154, Indonesia

Revised manuscript accepted for publication 21 August 2000
40,000 years ago, are littered with orang-utan teeth (Hooijer, 1961; Rijksen, 1978, 1982). It is easy to imagine what happened. The sluggish orang-utans make very easy targets for hunters, and their reproductive rate is so slow (Leighton et al., 1995) that it is easy to eradicate orang-utans locally.

Why are there still orang-utans in Sumatra and Borneo, when they have become extinct in the rest of the range? The reason probably is that human densities in these dense rain forests have always been relatively low, especially in the extensive swamp areas and in the rugged mountains of Aceh, so animals have always had refugia. Especially during the last century, however, human densities have risen dramatically and people have penetrated everywhere. So, it is telling that the current distributions of orang-utans on both Borneo and Sumatra tend to coincide with areas where there are no nomadic hunters (MacKinnon, 1992), and religious taboos forbid hunting of orang-utans by non-tribal residents (Rijksen \& Meijaard, 1999; C.P. van Schaik, unpublished data).

During 1994-1998, Rijksen \& Meijaard (1999) mapped the current range in Borneo and Sumatra. A geographic information system (GIS) based on satellite images was used to identify discrete forest blocks, and for each of these blocks they established two features: (i) the presence of orang-utans, as determined by visits and interviews, literature review, and a questionnaire sent to all active logging concessions in Kalimantan, the Indonesian part of Borneo and (ii) current land use (e.g. protected area, protection forest, logging concession, etc.). Thus, using conservatively estimated densities, they could estimate the remaining distribution area and 
degree of fragmentation, as well as the numbers remaining on each island. Their findings show that during the past century, Sumatran and Bornean orangutan numbers have declined by over 90 per cent. Total numbers of animals may not, however, be indicative of a species' conservation status if the habitat is highly fragmented. Because orang-utans are very poor dispersers, shunning non-forest habitat except in extreme discomfort, orang-utans are increasingly confined to isolated populations.

As a result of survey work by van Schaik et al. (1995a and unpublished data), and the recent effort by Rijksen \& Meijaard (1999), the distribution of orang-utans in Sumatra is known with some precision. Several scattered populations occur around and perhaps even south of the equator. However, these are thought to be extremely small relics (although a sizeable population might exist in the unprotected Angkola region, south of Sibolga), and may even belong to another so far undescribed species of great ape (locally referred to as 'orang pendek'; D. Chivers, pers. comm.). Orang-utans are concentrated in the northern part of the island, where they reach high densities locally. In this paper, we present a study of the changes in orang-utan numbers in their major Sumatran stronghold, the Leuser Ecosystem (Indonesia). In a companion paper (Robertson \& van Schaik, 2001), we examine the underlying causes and offer recommendations for reducing the threats.

\section{The Leuser orang-utans}

The Leuser Ecosystem covers c. 25,000 sq km (see Fig. 1 for boundaries and topographical names). It extends over 75 per cent of the Sumatran orang-utan distribution area north of Lake Toba, where all the significant Sumatran orang-utan populations are located (Rijksen \&
Fig. 1 Location of the Leuser Ecosystem and the main areas and rivers within its boundaries (inset shows its location in Sumatra).

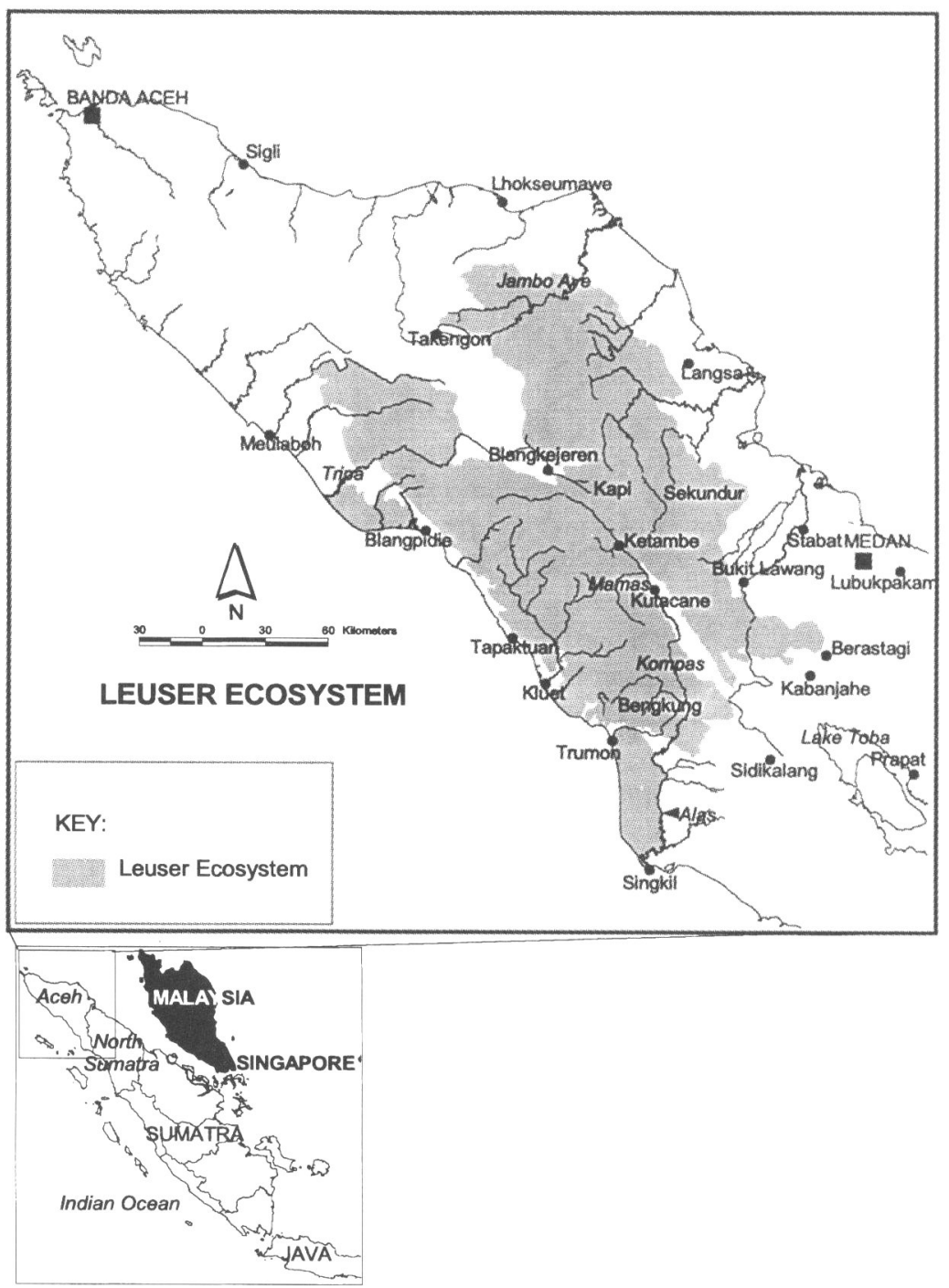


Meijaard, 1999). It probably contains an even greater proportion of the actual numbers, because the high densities reached in parts of Leuser are not found anywhere else. A healthy population in Leuser is vital, therefore, for the survival in the wild of the Sumatran subspecies. The Leuser Ecosystem, first established in 1995, and expanded in 1998, is a legal entity (based on Presidential Decree No. 33/1998) to be managed for conservation, and was designed to contain viable populations of all major wildlife species. The Leuser Ecosystem encompasses the designated Gunung Leuser National Park, an amalgam of various protected areas covering c. $9000 \mathrm{sq} \mathrm{km}$. It also contains large stretches of protection forest, various logging concessions, and several transmigration areas; the licenses of these were given out before the Ecosystem was established. The orang-utan distribution around the Leuser Ecosystem, differentiated by habitat quality, reflecting the situation of early 1993 is shown in Fig. 2.

The orang-utans in Leuser (Plate 1) have been studied for almost three decades at Ketambe (Rijksen, 1978; Sugardjito et al., 1987; Utami \& Mitra Setia, 1995), since
1992 at Suaq Balimbing (van Schaik, 1999), and in shorter observational studies in the Renun area (MacKinnon, 1974) and Soraya (D. Priatna, unpublished data). Leuser orang-utans differ from their Bornean counterparts in having higher average densities, a higher tendency to form parties, more intensive social behaviour, and a lower tendency to force matings (Delgado \& van Schaik, 2000). Conservation efforts should strive therefore to protect populations of both subspecies. In some sites in the Leuser Ecosystem, the orang-utans show routine use of at least two kinds of feeding tools (van Schaik et al., 1996). The geographical distribution of this tool use (van Schaik \& Knott, in review) attests to a material culture on par with chimpanzees. Conservation efforts should, therefore, strive to preserve multiple Sumatran populations.

In Sumatra, over the past decade or so there has been many new logging concessions and much conversion to industrial agricultural estates or transmigration areas. Since the end of 1998, after the fall of the Soeharto régime and the ensuing period of near-anarchy, illegal logging and conversion increased dramatically (Robert-

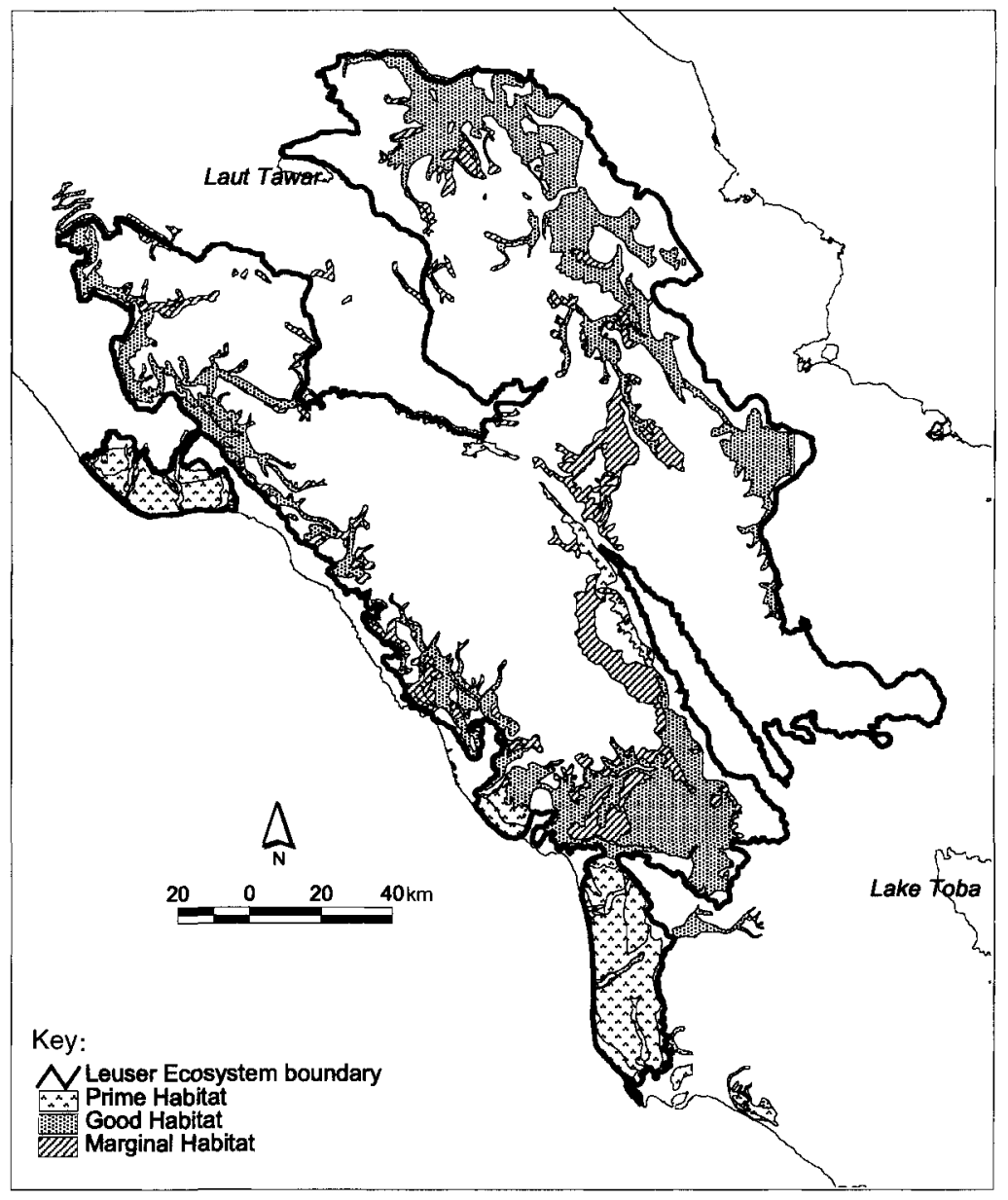

Fig. 2 Distribution of orang-utan habitat in the Leuser Ecosystem, reflecting the situation in early 1993 (see text for habitat classification). 


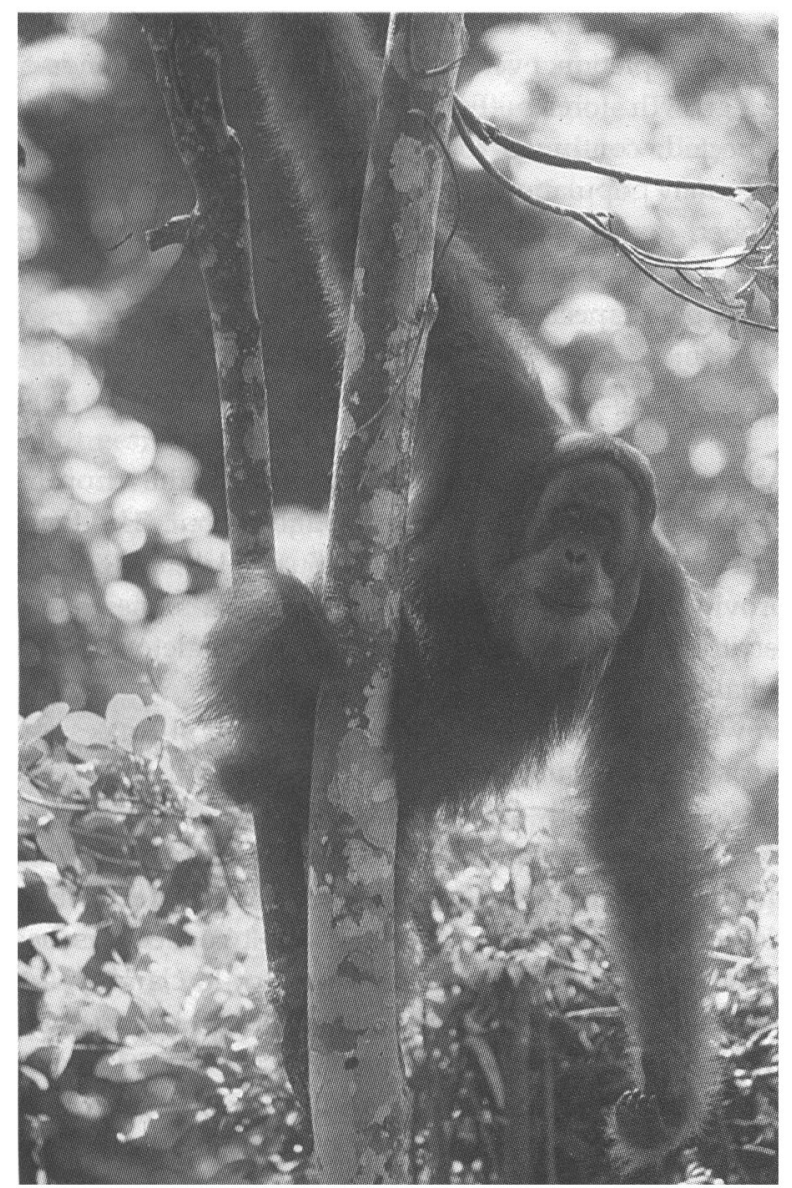

Plate 1 Large subadult male orang-utan, Leuser Ecosystem (Mr Perry van Duynhoven).

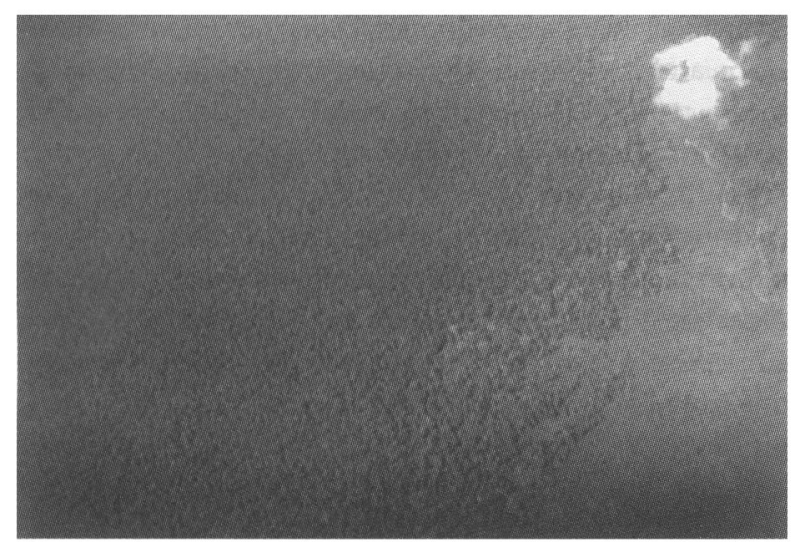

Plate 2 Aerial view of intact coastal swamp forest in Kluet (prime orang-utan habitat), as well as 4-year-old open clear-cut forest (lower right) (Mr Perry van Duynhoven).

son \& van Schaik, 2001). Hence, it is vital to obtain a detailed estimate of the Leuser orang-utans' numbers, as well as an estimate of the trends in these numbers.
To estimate these numbers and changes in them, we need information on densities in relation to habitat and on the effects of various intensities of logging on orangutan densities. For these reasons, these two issues are addressed first.

\section{Density variation in Leuser}

Several years of surveys and nest census (van Schaik et al., 1995a and unpublished data; S. Wich and R. Buij, unpublished data) have yielded a good impression of densities by habitat in Leuser (see also Fig. 2). Orangutans are largely lowland animals, being rare above $1000 \mathrm{~m}$ a.s.l. and virtually absent above $1500 \mathrm{~m}$ (altitudinal limits are even lower in Borneo where the mountain ranges also tend to be lower and thus vegetation zones are more altitudinally compressed; see van Schaik, 1996a; Rijksen \& Meijaard, 1999). There are two major areas in Leuser of orang-utan concentration ('prime habitat' in Fig. 2): the coastal swamps (Plate 2), where densities locally reach 7 or more individuals per $\mathrm{sq} \mathrm{km}$, and mean densities are in the order of 3-5 individuals per sq $\mathrm{km}$, and parts of the upper Alas valley, where the best areas contain over 6 individuals per sq $\mathrm{km}$, and mean densities are around 3 individuals per sq $\mathrm{km}$. Elsewhere in the lowlands, densities vary between 0.5 and 2 individuals per sq $\mathrm{km}$, with the higher densities in the river valleys, especially floodplains ('good habitat'). Densities are up to 1 individual per sq $\mathrm{km}$ in most upland areas up to c. $1000 \mathrm{~m}$ (higher on some plateaux) with occasional pockets of higher densities in the valleys ('marginal habitat'). At even higher altitudes, orang-utans are still found, but their density tends to be much lower, and in most places probably reflects the presence of floaters (animals without a fixed range) rather than true residents. These areas are therefore ignored in Fig. 2.

The reasons for these patterns are increasingly understood. Djojosudharmo \& van Schaik (1992) demonstrated at Ketambe that orang-utans prefer to use tree species with fruit containing soft pulp (rather than dry or fibrous fruits), both the unspecialized berries (including figs) eaten by a large array of birds and mammals and the fruits with thick husks eaten only by mammals, especially primates. van Schaik (1996a) generalized this result, showing that the availability of fruit with soft pulp (estimated in fruit censuses as their proportion among total fruit to avoid the problem of seasonality in total abundance) is a good predictor of orang-utan density.

This pattern explains the major patterns in orang-utan density. Firstly, although fruit production in general declines with altitude, the production of fruits with soft pulp does so more steeply (Djojosudharmo \& van Schaik, 1992), thus producing the overall altitudinal 
gradient. Secondly, alluvial and floodplain habitats are more productive than upland habitats, and contain a higher proportion of soft-pulp fruits (van Schaik \& Mirmanto, 1985). Thirdly, the exceptions, e.g. high densities on the upper slopes in the upper Alas valley (above Kutacane), prove the rule. These fertile lands have much less acidic soils than commonly seen in the region and, therefore, have exceptionally high densities of strangling figs (van Schaik, 1996b), which produce large crops of soft-pulp fruits at relatively short intervals. Finally, this pattern may even explain why densities on the eastern foothills and lowlands are lower on average than in the west, because the fertile alluvial plains and hillsides with high densities of strangling figs and other soft-pulp fruits appear to be less common in the eastern region.

\section{Orang-utans and logging}

It has long been known that orang-utans do not respond well to logging. Although the design of most studies was necessarily imperfect, their findings strongly converge: in selectively-logged areas (logging concessions), densities decrease on average by 60 per cent of prelogging levels (Rijksen, 1978; Davies \& Payne, 1982; Payne, 1987; van Schaik et al., 1995a; Sugardjito, unpublished data). A recent study by Rao \& van Schaik (1997) near Ketambe demonstrated that individual animals that had the choice between unlogged and selectively logged forest, tended to avoid the logged forest. When they did enter the logged area, they showed a relative shift from frugivory to folivory, corresponding to the 60 per cent lower abundance of fruit. They also travelled more, consistent with a reduction in the continuity of the canopy. These same factors are expected to hold more generally: although in dryland forests logging targets mainly dipterocarps, which are not a major component of the orang-utan's diet, the collateral damage is serious enough to kill many fruit trees. In addition, of course, the very irregular canopy increases the amount of vertical climbing, and thus makes travel more expensive (cf. Wheatley, 1982).

If the impact of logging stopped there, the losses would be limited and the prospects for population recovery would be auspicious. Unfortunately, in this region, selective logging is rarely followed by the 30 - to 40-year rest period prescribed by law. Instead, timber removal continues, illegally now, until just about all of the timber-sized trees of commercially valuable species are gone. In one such area, near the Soraya field station, D. Priatna (pers. comm.) showed that orang-utan density fell by some 90 per cent within a year after selective logging followed by continued timber poaching (from 4.2 pre-logging to $c .0 .4$ individuals per sq $\mathrm{km}$ ). Orang- utans continue to be very rare in the years following timber depletion, even in the small remaining islands of old-growth forests (Ferdian, pers. comm.). Thus, as expected, continued logging effectively eliminates orang-utan populations in the secondary forest left after timber depletion. Although less is known of other species, this conclusion is likely to hold good for many old-growth specialists.

\section{Mechanisms of decline}

An important question is how exactly the drop in density following logging is brought about. The longterm studies at Ketambe and Suaq Balimbing have provided us with some answers. As orang-utans are not territorial (Rijksen \& Meijaard, 1999; Singleton \& van Schaik, in press), one might surmise that animals simply crowd into the unaffected forests adjacent to concession areas or areas subject to illegal logging, but this is not what we generally see. Observations at several locations near areas with active deforestation or selective logging show that there is hardly any increase in local densities. Ketambe, for instance, over the last two decades has gradually become a small peninsula of lowland forest, yet the density of orang-utans has remained steady, at about 5 individuals per sq $\mathrm{km}$, since the early 1970s. A detailed nest census programme at Suaq Balimbing, in operation since early 1994, has so far failed to demonstrate a clear increase over time, despite the deforestation of a large patch of forest right next to the site, and continuing habitat degradation caused by illegal logging in all other adjacent parts. A shorter, but equally detailed, nest census programme to the south of the core study area, where logging was continuously taking place and gradually approaching the plots during the study period, showed no increase in new nests (I. Singleton, unpublished data).

The implication of these findings is that orang-utans are much less flexible in their use of space than generally thought. At Suaq Balimbing, we have noted a general dichotomy between residents and transients (Singleton \& van Schaik, in press). Residents are highly conservative in their range use over the years. Some of the Suaq residents, for instance, who lost part of their home range as a result of deforestation across the river, have not substantially expanded their range on the study area side of the river. Obviously, this could lead to localized crowding, although other residents may respond with more biased use of their own home ranges by moving away from the more crowded parts.

Transients, on the other hand, should be able to avoid the damaged areas after logging. However, our data suggest that the overall intensity of use by residents is much higher than by transients (although it is not 
known whether this conclusion also applies to other sites). This explains why the density increases in areas near foci of selective logging are negligible. Thus, the reduction in local densities caused by selective logging is only partly because of the reduction in visits by transients, but must to a considerable extent be the result of resident animals being eliminated altogether from the population, succumbing to disease, or getting shot or captured. The latter cause of death is increasingly common because of conflicts with local people for fruit trees, especially durian.

In conclusion, there is no evidence for appreciable crowding effects in habitat patches adjacent to logging areas. Therefore, we can use equilibrium densities for the estimation of remaining numbers.

\section{Changes in the number of orang-utans in the Leuser Ecosystem}

Estimates of the total number of orang-utans in the Leuser population have been provided at various times. Most numbers, however, referred to the smaller Gunung Leuser National Park, c. $9000 \mathrm{sq} \mathrm{km}$, which was estimated to contain between 4000 and 6000 individuals, most probably near 6000, around 1990 (van Schaik et al., 1995b). The first estimates for the whole Leuser Ecosystem were obviously higher than those of the national park (van Schaik et al., 1995b: c. 9200), but since then the Leuser Ecosystem has been expanded to c. $25,000 \mathrm{sq} \mathrm{km}$, and the total number should be around 10,000 or more. The more recent conservative estimate by Rijksen \& Meijaard (1999) for the Leuser Ecosystem (pre-expansion, c. 17,900 sq km) was c. 6950. At the time of its declaration therefore the Leuser Ecosystem contained the largest contiguous orang-utan population in the world.

Here, we will develop a new estimate based on the most detailed information of orang-utan distribution and density estimates produced in the Leuser Ecosystem itself as currently delineated, representing the situation of early 1993. We will use this estimate as the baseline to assess the effects of several recent developments: (i) losses in the available habitat in the best habitats: the coastal swamps and the upper Alas valley and (ii) the conversion of many areas legally allocated to timber production as logging concessions to logged-over wasteland or agricultural land. Thus, we will estimate their impacts on orang-utan numbers to assess the decline of Leuser's orang-utan populations.

\section{Methods}

The period covered is early 1993 to mid-1999. As our baseline we will use the distribution of forest provided by a Geo-Image satellite image recorded in early 1993. This interpreted image was corrected on the basis of extensive knowledge of the situation in the field. Later forest distribution estimates are based on a combination of intensive field observations, photo-mosaics compiled from numerous overflights by small fixed wing airplane at $8000 \mathrm{ft}$ altitude, and subsequent Landsat satellite images, the most recent one dating from late 1998. On the photo-mosaics, forest can easily be classified as unlogged, selectively logged or intensively logged, but on the satellite images this is impossible. Hence, for many areas, we use our extensive field notes and staff reports to estimate the proportion of each forest block (e.g. a particular logging concession) actually subject to the various treatments (none, light logging, heavy logging, conversion). The delineations of the various official forest use and conversion licenses and transmigration areas were provided by various government agencies.

\section{Orang-utan numbers in the Leuser Ecosystem in early 1993}

Three classes of orang-utan habitat are shown in Fig. 2, corresponding to estimates of mean densities of 3.5, 1.5 and 0.75 individuals per sq $\mathrm{km}$, respectively (Table 1 ). This yields a total estimated number of orang-utans (always multiplied by a 0.8 safety factor, to take into account pockets of reduced density or absence of orangutans caused by local hunting, unexplained unsuitability of local habitat conditions or unusually large distance from edges or rivers; see also van Schaik et al., 1995b) of c. 12,000 for the entire Ecosystem around early 1993 (Table 1). This number may slightly overestimate the amount of intact forest in logging concessions that had just begun operations, and thus the number of orangutans, by at most 500 individuals (giving a more conservative estimate of 11,500 ).

Thus, only a few years ago these numbers seemed reassuring, giving cause for optimism about the

Table 1 Estimated number of orang-utans in the Leuser Ecosystem in early $1993^{a}$.

\begin{tabular}{lllll}
\hline & & \multicolumn{3}{c}{$\begin{array}{l}\text { Area inside } \\
\text { Leuser }\end{array}$} \\
$\begin{array}{llll}\text { Habitat } \\
\text { quality }\end{array}$ & $\begin{array}{l}\text { Density } \\
\text { class }\end{array}$ & $\begin{array}{l}\text { Mean density } \\
\text { (ind per sq km) }\end{array}$ & $\begin{array}{l}\text { Ecosystem } \\
\text { (sq km) }\end{array}$ & $\begin{array}{l}\text { number of } \\
\text { orang-utans }\end{array}$ \\
\hline $\begin{array}{l}\text { Prime } \\
\text { Good }\end{array}$ & High & 3.5 & 1801 & 5040 \\
Marginal & Low & 1.5 & 4863 & 5840 \\
Total & & 0.75 & 1937 & 1160 \\
\hline
\end{tabular}

${ }^{a}$ Assuming a 0.8 safety factor in all calculations (see text for explanation). 
orang-utan's prospects in northern Sumatra. They are higher than the more conservative estimate of Rijksen \& Meijaard (1999) because we could use more detailed distribution information and locally-appropriate density estimates rather than average values for the whole range.

We will now turn to the impact of the recent developments.

\section{The swamps}

Three coastal swamps in the Leuser Ecosystem are critical for orang-utans (from north to south: Tripa, Kluet, Trumon-Singkil). They are a mixture of seasonal back swamps on mineral soils or shallow peat and peat swamps of variable thickness. In particular, the large Trumon-Singkil swamp, originally over $1000 \mathrm{sq} \mathrm{km}$, must have represented the largest single population of orang-utans in the world. During the last few years, however, all areas have been seriously degraded by a variety of developments:

\section{Conversion to oil palm plantations}

Most of the Tripa swamp, some of the northern parts of Trumon-Singkil, and small peripheral areas of Kluet have been or are being converted into oil palm plantations, which do remarkably well for now, although subsidence effects on thicker peat may start to affect productivity. The deep drainage channels affect the swamp up to $1 \mathrm{~km}$ outside the converted area.

\section{Transmigration areas}

In Trumon-Singkil, several transmigration projects have not only led directly to habitat loss but also to the presence of a large contingent of people available to assist in legal and illegal logging and other extractive operations degrading the swamp.

\section{Illegal logging}

Wherever logs can be pulled out or floated out during floods, i.e. usually up to 1 or $1.5 \mathrm{~km}$ from waterways, all floatable valuable timber has been or is being removed, regardless of the legal status of the land. This is the major source of degradation in the relatively small Kluet area, but it also affects the whole perimeter of TrumonSingkil and especially the coastal zone in Tripa, where most other parts have already been converted.

The orang-utan's decline in these swamps is summarized in Table 2. For each swamp area, a weighted mean density is estimated, based on two components: (i) swamp-dependent density estimates for each habitat based on extensive surveys from 1992; (ii) estimates of the relative proportion of back swamp, transitional swamp and peat swamp. Thus, of the original estimated 5350 orang-utans only 2500 remain, a loss of c. 2850 since early 1993 (Table 2). Because this estimate reflects the situation at the end of 1998, it does not take the latest wave of illegal logging into account. This illegal logging targets two of the three top orang-utan food species (Neesia cf. aquatica and Sandoricum beccarianum; C.P. van Schaik, unpublished data).

\section{The upper Alas valley}

The Alas valley itself, and especially the lower slopes of the mountain range on its western flank, are rich orangutan habitat, with an estimated mean density for the areas below $1000 \mathrm{~m}$ of around 3 individuals per sq $\mathrm{km}$ (see also Rijksen, 1978; van Schaik et al., 1995a).

The upper Alas valley contains no official logging concessions. Nonetheless, deforestation, mainly for shifting agriculture, has been a problem for decades, with both the designated Gunung Leuser National Park and protection forest (forest in which no commercial logging is allowed) being targeted. Forest loss is continuing and probably accelerating, with serious incursions into the Ecosystem, sanctioned by the local government, made along river valleys (Kompas, Mamas) and generally up the slopes of the rift valley through which River Alas flows. Large-scale fires in 1998 , exacerbated by this deforestation, added to the problem.

Table 2 Changes in the estimated number of orang-utans in the three swamp forests of Aceh Selatan ${ }^{\circ}, 1993-1998$.

\begin{tabular}{|c|c|c|c|c|c|c|c|}
\hline \multirow[b]{2}{*}{ Swamp area } & \multirow{2}{*}{$\begin{array}{l}\text { Weighted } \\
\text { mean density } \\
\text { (ind per sq km) }\end{array}$} & \multirow{2}{*}{$\begin{array}{l}\text { Original area } \\
(\mathrm{sq} \mathrm{km})\end{array}$} & \multirow{2}{*}{$\begin{array}{l}\text { Estimated } \\
\text { remaining } \\
\text { area }(\mathrm{sq} \mathrm{km})\end{array}$} & \multicolumn{3}{|c|}{ Estimated number } & \multirow{2}{*}{$\begin{array}{l}\text { Animals } \\
\text { lost }(\%)\end{array}$} \\
\hline & & & & Original & Current & Lost & \\
\hline Tripa & 2.85 & 595 & 225 & 1350 & 510 & 840 & 62 \\
\hline Kluet & 5.45 & 165 & 90 & 700 & 390 & 310 & 44 \\
\hline Trumon-Singkil & $4.00^{b}$ & 1040 & 550 & 3300 & 1600 & 1700 & 52 \\
\hline Total & & 1800 & 865 & 5350 & 2500 & 2850 & 53 \\
\hline
\end{tabular}

${ }^{a}$ All estimates use a 0.8 safety factor.

${ }^{b}$ Original value, for current estimates a density of 3.6 is used because of biased loss of optimum habitat. 
An estimate of recent losses was based on the late 1998 Landsat image and photo-mosaics produced by the Leuser Management Unit (LMU) during overflights in mid-1998. From this comparison, we estimate that an additional $82 \mathrm{sq} \mathrm{km}$ of good orang-utan habitat was lost in the upper Alas valley since the early 1993 baseline was established, translating into an estimated loss of $(82 \times 0.8 \times 3)=$ c. 200 orang-utans. Again, these numbers do not take into account the recent wave of illegal logging and, therefore, seriously underestimate the loss since the inception of the Leuser Ecosystem: 10 large trucks each day were transporting timber illegally cut from this part of the national park during most of 1999.

\section{Logging concessions}

Most of the Leuser Ecosystem outside the designated National Park consists of logging concessions (Fig. 3). In the non-swampy part of the Leuser Ecosystem, the total area allocated to logging concession ('forest utilization license' in Fig. 3) at the time the Ecosystem was declared in 1995 was $724,227 \mathrm{ha}$, or roughly $7250 \mathrm{sq} \mathrm{km}$.
Visits around Leuser over the past few years have shown a systematic pattern of conversion and degradation of logging concessions following the first cutting cycle:

- Timber poachers, often with the tacit or allegedly active approval of the concession holders, revisit the logged-over areas, or work in areas not yet covered by the concessionaire. Where timber poaching is intensive, this turns the forest into a secondary jungle, in which the only tall trees are of commercially unprofitable species.

- All or parts are legally or illegally converted to largescale agricultural plantations, mainly oil palm (HGU in Fig. 3), softwood plantations (HTI and HPHTI) or mixed transmigration-plantation areas (PIR).

- The concession area is invaded by spontaneous settlers who practise various forms of extensive agriculture or establish their own plantations.

These changes are actually part of a systematic trend. Logging concessions, although by law intended to be used indefinitely for timber production in natural forests, provide the roads that can be used for further land development and make conversion easier by
Fig. 3 Distribution of legally-planned activities inside and around the Leuser Ecosystem: forest utilization licenses (referring to selective timber extraction), and two forms of forest conversion (see text for explanation of forest conversion).

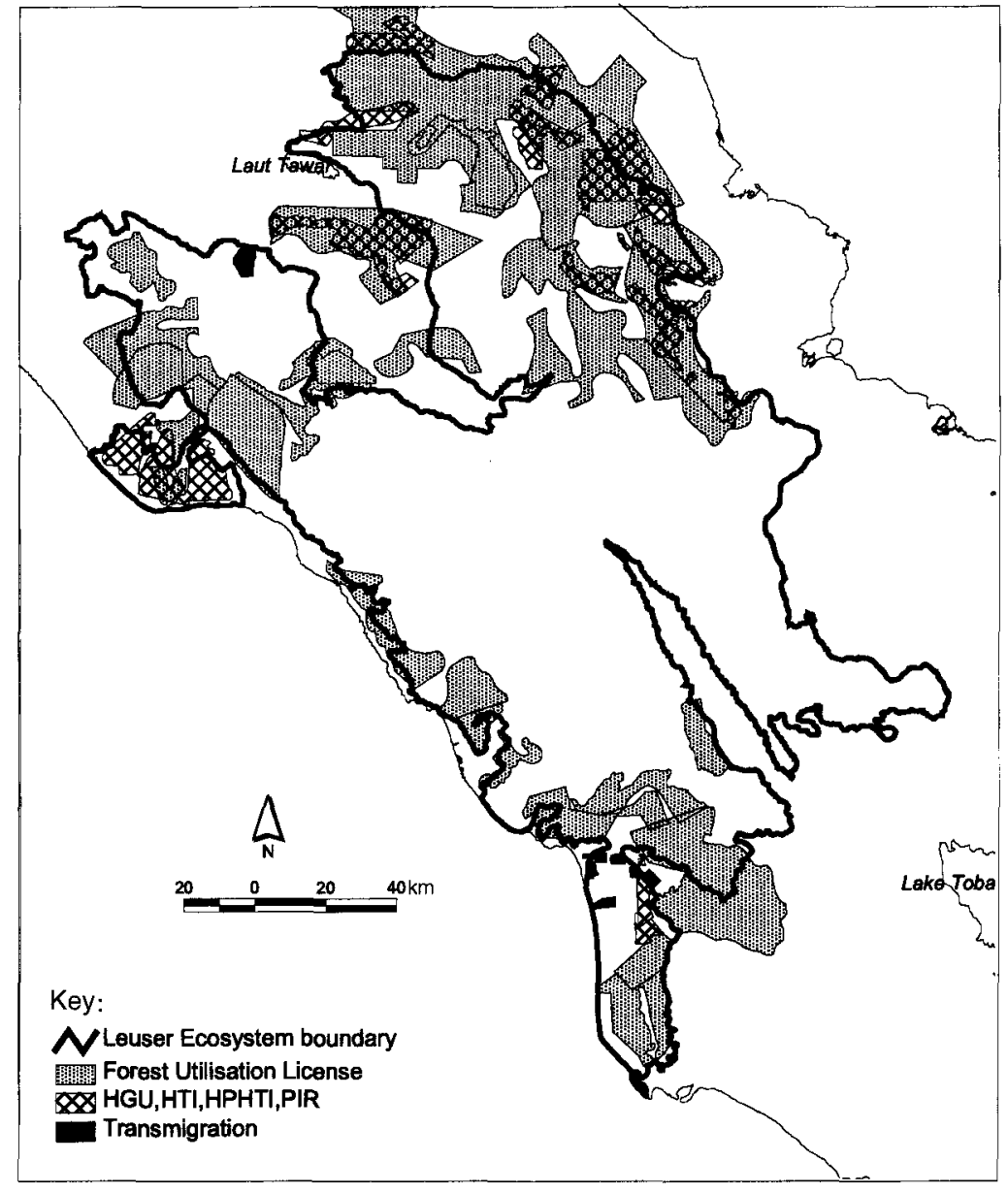


removing the largest trees. Transmigration projects often follow, providing the labour for the subsequent establishment of large agricultural estates, or the occasional forest plantation. Usually, some areas are also set aside unilaterally by local governments for spontaneous settlement by local people. Thus, the seemingly chaotic (and largely illegal) changes are in fact phases of a well-designed plan to develop the frontier. Several of the concessions that have been logged completely have subsequently undergone legal changes in their land use status (see Robertson \& van Schaik, 2001 for details)

Each of these developments spells the end of viable orang-utan populations, because the habitat is irretrievably lost or is degraded to the extent that densities fall to well below 0.5 individuals per sq $\mathrm{km}$ after some years (see above). In effect therefore much of the area covered by these concessions should be discounted as orangutan habitat. Given the ubiquity of these developments, it is safe to assume that the only areas currently escaping this fate are the more remote parts of concessions still in operation, as well as most of the concessions operating in the far north of the Ecosystem, which were relatively well managed and are only now beginning to be invaded by illegal loggers and transmigrants.

The estimated loss of orang-utans was based on the following estimated parameters. Firstly, we estimated that at the end of 1998, of the total of $c .7250 \mathrm{sq} \mathrm{km}$ of logging concession area outside the main swamps, $3500 \mathrm{sq} \mathrm{km}$ was still forest, of which $2000 \mathrm{sq} \mathrm{km}$ was still unlogged and $1500 \mathrm{sq} \mathrm{km}$ had been selectively logged, whereas some $3750 \mathrm{sq} \mathrm{km}$ had been converted or degraded to the point it could not support orangutans (Table 3). (This estimate was arrived at by estimating the proportion for each separate concession, and calculating an unweighted mean.) Secondly, as explained above, we assume that selectively-logged forest retains 40 per cent of the original orang-utan density. Thirdly, we estimate that before the logging started $c .65$ per cent of the concession area contained orang-utan habitat (mainly good, but some poor), with mean densities of 1.25 individuals per sq km. Fourthly, because the flatter, and hence more accessible lowland and alluvial parts are the first to be logged, at present only 60 per cent of the concessions represents orangutan habitat.

The results, presented in Table 3 , indicate that, since the start of the logging concessions, Leuser has lost some 3200 orang-utans. It is more difficult to estimate how many have been lost since early 1993, because detailed mapping of the extent of the damage is difficult from the early satellite image. A linear rate of loss would suggest a reduction of 320 orang-utans per year, and hence a loss of 1900 in total since early 1993, but we know the rate of forest loss and degradation has been steeply accelerating since the start of serious logging in 1988 (few concessions were active before that year). Hence, a more realistic estimate would be that $c$. 2500 orang-utans have lost their habitat, and thus their lives, in Leuser's logging concessions since early 1993.

\section{Numbers remaining}

These trends can be combined into the following estimated changes in orang-utan numbers. Since early 1993, the Leuser Ecosystem has lost around 2500 orangutans in the logging concession areas, about 2850 from the coastal swamps, and roughly 200 from the upper Alas valley, giving a total loss of c. 5550 orang-utans, leaving c. 6500 in mid-1999. If we accept that the Leuser Ecosystem contained c. 12,000 orang-utans in early 1993, this means that over the past 6 years or so Leuser has lost almost half (46 per cent) of its orang-utans, or 43 per cent if we use the more conservative estimate. Thus, legal and illegal logging and forest loss have been responsible for the death of some 1000 orang-utans per year on average. As the rate of forest loss and degradation has increased dramatically in the past two years,

\begin{tabular}{|c|c|c|c|c|}
\hline \multirow[b]{2}{*}{$\begin{array}{l}\text { Category by } \\
\text { late } 1998\end{array}$} & \multirow[b]{2}{*}{$\begin{array}{l}\text { Area } \\
(\mathrm{sq} \mathrm{km})\end{array}$} & \multicolumn{3}{|c|}{ Number of orang-utans } \\
\hline & & $\begin{array}{l}\text { c. } 1988 \\
\text { ( } 65 \% \text { mainly } \\
\text { good habitat) }\end{array}$ & $\begin{array}{l}\text { Late } 1998 \\
(60 \% \text { mainly } \\
\text { good habitat) }\end{array}$ & $\begin{array}{l}\text { Lost between } \\
1988 \text { and } 1998\end{array}$ \\
\hline Converted/degraded ${ }^{b}$ & 3750 & 2440 & 0 & 2440 \\
\hline Selectively logged ${ }^{b}$ & 1500 & 970 & 360 & 610 \\
\hline Pristine & 2000 & 1300 & 1200 & 100 \\
\hline Total & 7250 & $4710^{c}$ & 1560 & 3150 \\
\hline
\end{tabular}

Table 3 Changes in the estimated number of orang-utans in timber concessions in non-swamp forest inside the Leuser Ecosystem boundaries, since the start of their operations ${ }^{a}$.

\footnotetext{
${ }^{a}$ Assuming a 0.8 safety factor in all calculations.

bAssumed pristine in 1988.

'The estimate of over 4700 orang-utans in Leuser's concessions cannot be compared directly with Table 1, because it refers to the 1988 situation when the orang-utan distribution was more extensive than shown in Fig. 1 (the basis for Table 1).
} 
the rate of loss since 1998 has been well over 1000 orangutans per year.

It is important to assess the robustness of this dramatic estimate. Errors may have crept into density estimation, but such errors would mainly affect the absolute values of the estimates, and have only a minor effect on the estimated decline, because they have a similar effect on the estimates of the baseline situation and the remaining numbers. The effect of selective logging on densities has been repeatedly confirmed, and is only a marginal factor in the overall estimate.

The distribution data are unlikely to contain much error, although some discrepancies were unavoidable. Thus, for Table 1 we used a three-way classification of habitats for the whole Leuser Ecosystem, whereas for Table 2 we could derive detailed estimates for each swamp based on a fine-grained habitat analysis. Any discrepancy is small, however.

A more serious possible error is that we may have overestimated the decline by ignoring highland orangutans and/or overestimating habitat loss. At higher altitudes, especially in the forests west of the Alas River and in Kapi, orang-utans do occur above $1000 \mathrm{~m}$. Here, we only included those highland areas with confirmed orang-utan populations, because the parts above $1000 \mathrm{~m}$ farther away from lowland areas may well be all but empty. There are also reasons to doubt whether any orang-utans found in the montane forests are selfsustaining demographically; instead, they may mainly represent non-reproducing floaters from the lowlands. If the montane areas do contain orang-utans, albeit at very low densities, the large area would suggest that we have underestimated the total number by approximately 1000 individuals. This is possible, although we do not think it likely. Moreover, whilst including them would reduce the estimated percentage decline to $c$. 42 per cent, it would obviously leave the absolute decline unaffected.

We may have overestimated habitat loss in the logging concessions. These estimates were necessarily crude and not easily improved without doing more detailed fieldwork in each concession. The trend is quite robust, however, we know of no example where some years after the logging ended, the concession area is not at least partly converted and/or does not contain seriously degraded forest. Thus, if our estimates are in error, they err in the time scale of the change, but not its direction.

\section{Projections}

The alarming decline in Leuser's orang-utan numbers over the past 6-7 years implies that the world's largest natural orang-utan population will be extinct in a decade or so, unless the current trend is stopped. In order to develop predictions, let us consider the possible scenarios for the coming decade, illustrated in Fig. 4.

The first scenario is optimistic. It assumes that law enforcement will be immediate and complete in the protected areas. It assumes that the whole Ecosystem will receive proper protection from now on, but that all land allocated to logging concessions and other land uses that lead to conversion (plantation [HGU], HTITrans, HTI, Transmigration) will be lost as orang-utan habitat. The remaining area of orang-utan range is estimated to contain c. 5400 individuals (Table 4), or about 1000 individuals fewer than estimated to be present today. We expect that this point could be reached in a few years.

This scenario is conservative. First, it ignores the negative impacts emanating from the boundaries of these designated conversion areas. Secondly, most of the remaining parts of the distribution range are very small pockets, unlikely to retain their orang-utans for long. Although it is possible that some of the least accessible

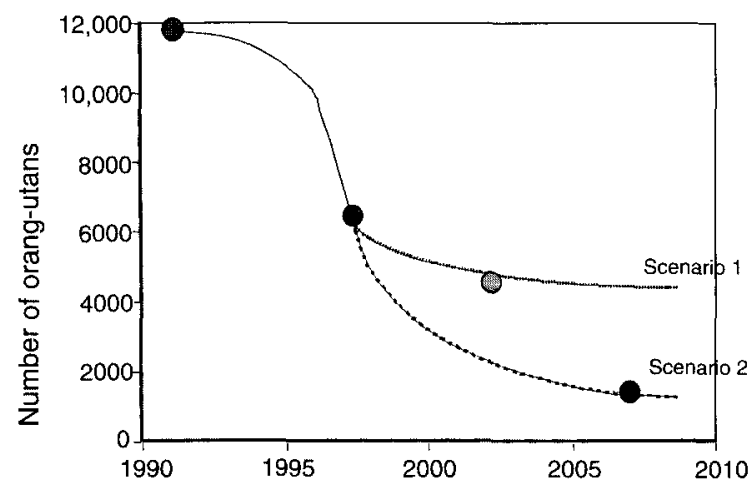

Fig. 4 Estimated loss in orang-utan numbers in the Leuser Ecosystem from late 1992 to late 1998, as well as two extrapolations, the first (Scenario 1) based on no losses inside protected areas, and the second (Scenario 2) based on current illegal logging rates.

Table 4 Estimated number of orang-utans remaining in Leuser Ecosystem if all land with specific allocation to non-forest land use is excluded.

\begin{tabular}{llll}
\hline Habitat & $\begin{array}{l}\text { Mean } \\
\text { density } \\
\text { quality }\end{array}$ & $\begin{array}{l}\text { Remaining } \\
\text { habitat inside } \\
\text { Leuser Ecosystem } \\
\text { (sq km) }\end{array}$ & $\begin{array}{l}\text { Estimated } \\
\text { number of } \\
\text { orang-utans }\end{array}$ \\
\hline Prime & 3.5 & $982(-130)^{h}$ & 2400 \\
Good & 1.5 & 1822 & 2200 \\
Marginal & 0.75 & 1404 & 850 \\
Total & & 4208 & 5450 \\
\hline
\end{tabular}

assuming a 0.8 safety factor in all calculations.

bubtracting the known habitat recently lost inside the National Park in Kluet and the upper Alas valley (Table 2 and text), but not any other losses inside the National Park. 
parts of the concessions will retain their natural forests, they are mainly in steep terrain at higher altitudes, and thus contain marginal habitat or no habitat at all. Thirdly, it ignores the losses occurring in protection forests and the national park apart from the upper Alas valley and the Kluet swamp. We know there are many such losses occurring all along its perimeter, but cannot easily quantify them. However, we think that the estimate of 5400 should be adjusted to at least 4500 to account for habitat already irrevocably lost at this moment.

At present, all the remaining forests that are accessible by road or river (and thus almost all prime orang-utan habitat) are subject to a seemingly unstoppable pandemic of illegal logging, regardless of their protection status. Thus, the second scenario assumes that only the economy of exploitation limits habitat loss, and therefore that much more habitat will be lost. First, all swamps outside the protected core of Kluet, i.e. including the remaining forest at Trumon-Singkil, are likely to be lost in the coming years. Most of Trumon-Singkil has received formal protection status on paper in 1998 but has not yet been gazetted. As there was no enforcement on the ground until the time of writing, it is being logged quite heavily at present. Secondly, logging is taking place inside the designated national park in all areas containing orang-utans (Bengkung, Kompas, Mamas, Sikundur, upper Kluet river valley, upper Alas river valley, Kapi, area above Pucuk Lembang, etc.). Thus, inside the national park only various patches of hill forest with marginal habitat are likely to remain, along with some heavily defended parts of prime or good habitat: (i) the core of Kluet swamp; (ii) the area around Ketambe-Gurah; and (iii) the upper reaches of the Besitang in Sikundur.

Under this more realistic scenario, the Leuser Ecosystem will retain perhaps 1500 orang-utans within a decade or so (c. 300 in both Kluet and the interior of Trumon-Singkil, c. 200 in both Ketambe-Gurah and Sikundur, and c. 500 in a variety of fragments in the uplands of the Bengkung, upper Lesten (Kapi), and tributaries of Alas and Kluet rivers).

It is clear that under the most optimistic scenario the number of orang-utans inside the Leuser Ecosystem will fall to some 4500 within a decade, divided over several distinct populations. Under the more realistic scenario that extrapolates current trends in illegal logging, however, their numbers may fall to less than 1500, divided over various isolated populations of uncertain viability. Even small increases in mortality are likely to lead to extinction of orang-utan populations, because of their extremely slow life histories (Leighton et al., 1995). We must conclude, therefore, that the orang-utan's future in Leuser, its most important stronghold in the world, is in serious doubt. Hence, efforts to break this trend are urgently needed (see companion paper: Robertson \& van Schaik, 2001).

The situation in Borneo is no better. Rijksen \& Meijaard (1999) estimate that the wave of forest fires engulfing the island in 1997/98 has caused the death of up to one-third of the remaining wild orang-utans. In the wake of this serious assault came the same wave of illegal logging and conversion as in Sumatra. As elsewhere, much of this timber poaching and illegal settlement is in protected areas, ironically the only unprotected tracts of land during anarchy. Thus, unless these developments can be stopped soon, no viable orang-utan populations will be left in the world within a decade.

\section{Acknowledgements}

The first author thanks the Wildlife Conservation Society for sustained funding of orang-utan studies, and Mike Griffiths, Azwar, Perry van Duynhoven, and the late Idrusman, for much help during the fieldwork. We are grateful to all colleagues in the Leuser Management Unit for extensive logistical support, and especially Elizabeth Purastiti and R. Tarigan for running the GIS analyses. K.A.M. thanks the Zoological Society of London for its support. Herman Rijksen and two reviewers provided useful comments. We thank the European Commission and the Government of Indonesia as the funding agencies for the Leuser Development Programme. This is Leuser Management Unit publication Number $11 / 2000$.

\section{References}

Brown, J.H. \& Lomolino, M.V. (1998) Biogeography (2nd edn). Sinauer Associates, Inc., Sunderland, MA.

Davies, A.G. \& Payne, J.B. (1982) A Faunal Survey of Sabah. World Wildlife Fund, Kuala Lumpur, Malaysia.

Delgado, R. \& van Schaik, C.P. (2000) The orang-utan (Pongo pygmaeus): behavioural ecology and conservation status: a tale of two islands. Evolutionary Anthropology, 9, 201-218.

Djojosudharmo, S. \& van Schaik, C.P. (1992) Why are orang utans so rare in the highlands? Altitudinal changes in a Sumatran forest. Tropical Biodiversity, 1, 11-22.

Hooijer, D.A. (1961) The orang-utan in Niah cave pre-history. Sarawak Museum Journal, 9, 408-421.

von Koenigswald, G.H.R. (1982) Distribution and evolution of the orang utan, Pongo pygmaeus (Hoppius). In The Orang Utan, its Biology and Conservation (ed. L. E. M. de Boer), pp. 1-15. Dr W. Junk Publishers, The Hague.

Leighton, M., Seal, U.S., Soemarna, K. et al. (1995) Orang-utan life history and vortex analysis. In The Neglected Ape (eds R. D Nadler, B. F. M. Galdikas, L. K. Sheeran and N. Rosen), pp. 97-107. Plenum Press, New York.

MacKinnon, J. (1974) The behaviour and ecology of wild orangutans (Pongo pygmaeus). Animal Behaviour, 22, 3-74. 
MacKinnon, J. (1992) Species survival plan for the orang-utan. In Proceedings of the International Conference on Forest Biology and Conservation in Borneo (eds G. Ismail, M. Mohamed and S. Omar), pp. 209-219. Center for Borneo Studies, Kota Kinabalu.

Payne, J.B. (1987) Surveying orang-utan populations by counting nests from a helicopter: a pilot survey in Sabah. Primate Conservation, 8, 92-103.

Rao, M. \& van Schaik, C.P. (1997) The behavioural ecology of Sumateran orang-utans in logged and unlogged forest. Tropical Biodiversity, 4, 173-185.

Rijksen, H.D. (1978) A Field Study on Sumatran Orang Utans (Pongo pygmaeus abelii Lesson 1827). H. Veenman \& Zonen, B.V., Wageningen.

Rijksen, H.D. (1982) How to save the mysterious 'man of the rain forest'? In The Orang Utan: Its Biology and Conservation (ed. L. E. M. de Boer), pp. 317-341. Dr W. Junk Publishers, The Hague.

Rijksen, H.D. \& Meijaard, E. (1999) Our Vanishing Relative: The Status of Wild Orang-Utans at the Close of the Twentieth Century. Tropenbos Publications, Wageningen.

Robertson, J.M.Y. \& van Schaik, C.P. (2001) Causal factors underlying the dramatic decline of the Sumatran orang-utan. Oryx, 35(1), 26-38.

van Schaik, C.P. (1996a) Does the orang-utan have a future? Population status in Gunung Leuser National Park. In Leuser: A Sumatran Sanctuary (eds C. P. van Schaik and J. Supriatna), pp. 249-258. YABSHI, Depok, Indonesia.

van Schaik, C.P. (1996b) Strangling figs: their role in the forest. In Leuser: A Sumatran Sanctuary (eds C. P. van Schaik and J. Supriatna), pp. 111-119. YABSHI, Depok, Indonesia. van Schaik, C.P. (1999) The socioecology of fission-fusion sociality in orang-utans. Primates, 40, 73-90.

van Schaik, C.P. \& Mirmanto, E. (1985) Spatial variation in the structure and litterfall of a Sumatran rain forest. Biotropica, $17,196-205$.

van Schaik, C.P. Azwar \& Priatna, D. (1995a) Population estimates and habitat preferences of orang-utans based on line transects of nests. In The Neglected Ape (eds R. D. Nadler, B. F. M. Galdikas, L. K. Sheeran and N. Rosen), pp. 129-147. Plenum Press, New York.

van Schaik, C.P., Poniran, S., Utami, S.S. et al. (1995b) Estimates of orang-utan distribution and status in Sumatra. In The Neglected Ape (eds R. D. Nadler, B. F. M. Galdikas, L. K. Sheeran and N. Rosen), pp. 109-116. Plenum Press, New York.

van Schaik, C.P., Fox, E.A. \& Sitompul, A.F. (1996) Manufacture and use of tools in wild Sumatran orang-utans. Naturwissenschaften, 83, 186-188.

van Schaik, C.P. \& Knott, C. (in review) Geographic variation in tool use on Neesia fruits in orang-utans. American Journal of Physical Anthropology.
Singleton, I.S. \& van Schaik, C.P. (in press) Orang-utan homerange size and its determinants in a Sumatran swamp forest. International Journal of Primatology.

Sugardjito, J., te Boekhorst, I.J.A. \& van Hooff, J.A.R.A.M. (1987) Ecological constraints on the grouping of wild orang-utans (Pongo pygmaeus) in the Gunung Leuser National Park, Sumatra, Indonesia. International Journal of Primatology, 8, 17-41.

Utami, S.S. \& Mitra Setia, T. (1995) Behavioural changes in wild male and female Sumatran orang-utans (Pongo pygmaeus abelii) during and following a resident male take-over. In The Neglected Ape (eds R. D. Nadler, B. F. M. Galdikas, L. K. Sheeran and N. Rosen), pp. 183-190. Plenum Press, New York.

Wheatley, B.P. (1982) Energetics and foraging in Macaca fascicularis and Pongo pygmaeus and a selective advantage of large body size in the orang-utan. Primates, 23, 348-363.

\section{Biographical sketches}

Dr Kathryn Monk is co-ordinator of the Research, Monitoring and Information Division of the Leuser Development Programme, Medan, Indonesia, as a consultant from the Zoological Society of London. She is a research associate of Dalhousie University, Halifax, Canada, and of Reading University, UK. A tropical ecologist, she has worked in Africa, the Middle East and South-east Asia. She is the author of The Ecology of Nusa Tenggara and Maluku (Oxford University Press).

Dr Yarrow Robertson is co-ordinator of the Conservation Management Division of the Leuser Development Programme, Medan, Indonesia. He studied the socioecology of pigtalled macaques in Leuser for his $\mathrm{PhD}$, and has been co-ordinating conservation activities of the Leuser Management Unit with local communities and enforcement agenices for the past 4 years. He is a member of the IUCN SSC Asian Rhino Specialist Group, and affiliated with the Wildlife Research Group, Department of Anatomy, Cambridge University, UK.

Dr Carel van Schaik is Professor of Biological, Anthropology and Anatomy, and co-director of the Center for Tropical Conservation, Duke University (Durham, NC, USA). A research associate of the Wildlife Conservation Society in New York, he has studied primate behavioural ecology, rain forest ecology and conservation policy, focussing on Leuser, for the past 23 years. He is a member of the IUCN Primate Specialist Group. 